\title{
Hindered Diffusion of Asphaltenes at Evaluated Temperature and Pressure
}

\author{
Semi-Annual Report \\ September 20, 1997 - March 20, 1998 \\ By \\ James A. Guin; Xiaofeng Yang \\ Surya Vadlamani
}

Work Performed Under Contract No.: DE-FG22-95PC95221

\author{
For \\ U.S. Department of Energy \\ Office of Fossil Energy \\ Federal Energy Technology Center \\ P.O. Box 880 \\ Morgantown, West Virginia 26507-0880 \\ By \\ Auburn University \\ Chemical Engineering Department \\ 230 Ross Hall \\ Auburn, Alabama 36849
}




\section{Disclaimer}

This report was prepared as an account of work sponsored by an agency of the United States Government. Neither the United States Government nor any agency thereof, nor any of their employees, makes any warranty, express or implied, or assumes any legal liability or responsibility for the accuracy, completeness, or usefulness of any information, apparatus, product, or process disclosed, or represents that its use would not infringe privately owned rights. Reference herein to any specific commercial product, process, or service by trade

name, trademark, manufacturer, or otherwise does not necessarily constitute or imply its endorsement, recommendation, or favoring by the United States Government or any agency thereof. The views and opinions of authors expressed herein do not necessarily state or reflect those of the United States Government or any agency thereof. 
Hindered Diffusion of Asphaltenes at Evaluated Temperature and Pressure

Semi-Annual Technical Report

Reporting Period Start Date: 09/20/1997 End Date: 03/20/1998

\author{
Authors: \\ James A. Guin \\ Xiaofeng Yang \\ Surya Vadlamani
}

Report Issue Date: 04/03/1998

DE-FG22-95PC95221--05

\author{
Auburn University \\ Chemical Engineering Department \\ 230 Ross Hall \\ Auburn, AL 36849
}




\begin{abstract}
During this time period, uptake experiments were performed at elevated temperatures up to $280^{\circ} \mathrm{C}$ for the adsorptive diffusion of a coal asphaltene in 1methylnaphthalene onto alumina catalyst pellets. Model simulation results showed that a mathematical model incorporating diffusion and adsorption mechanisms satisfactorily fitted the adsorptive diffusion of coal asphaltenes onto the alumina catalyst in a fairly wide temperature range of $55^{\circ} \mathrm{C}$ to $280^{\circ} \mathrm{C}$. The logarithm of the adsorption constant, obtained by simulating the experimental data with the model solution, was found to be linearly dependent on temperature. As temperature increased, the value of the adsorption constant decreased. On the other hand, the effective diffusivity of the asphaltene increased with temperature. These off-setting temperature dependencies resulting from the adsorption constant and the effective diffusivity compensated at least to some extent in the uptake process.
\end{abstract}


HINDERED DIFFUSION OF ASPHALTENES AT ELEVATED TEMPERATURE AND PRESSURE

\section{Table of Contents}

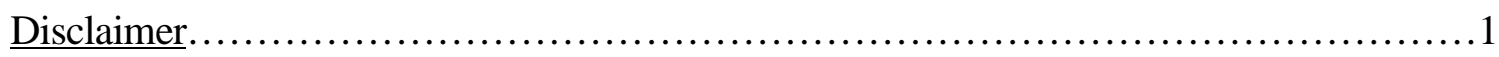

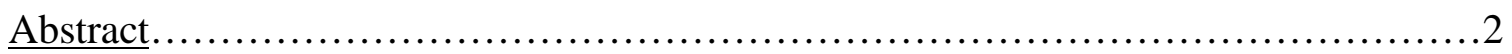

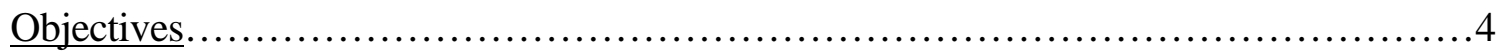

Executive Summary............................................................... 5

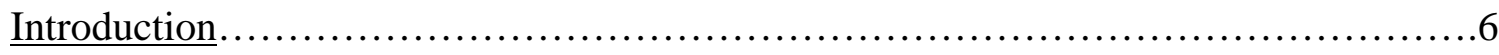

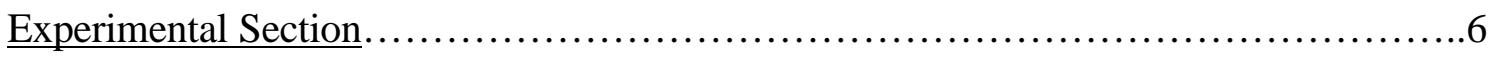

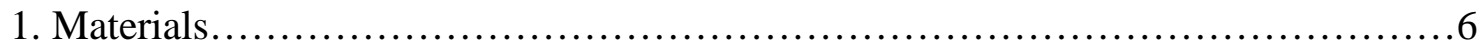

2. Apparatus and Procedures....................................................

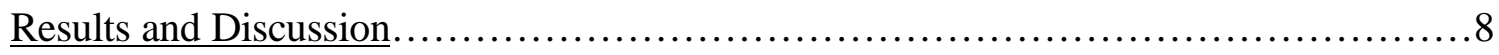

1. Diffusivities and Adsorption Constants of Asphaltenes at Different Temperatures....8

2. Model Simulation of Asphaltene Uptake into $\mathrm{Al}_{2} \mathrm{O}_{3} \ldots \ldots \ldots \ldots \ldots \ldots \ldots \ldots \ldots \ldots \ldots$

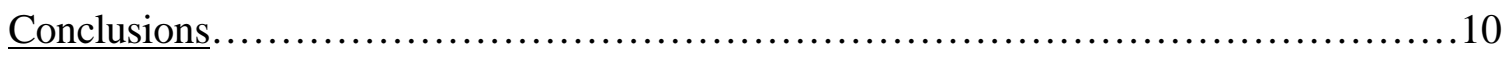

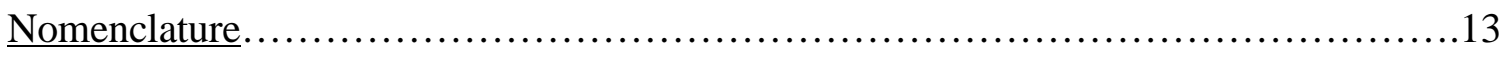

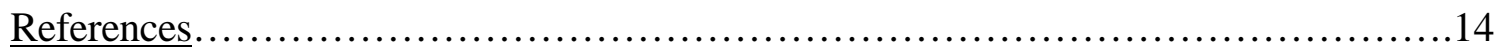

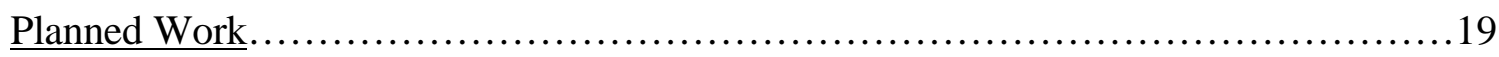




\section{Objectives}

1. To investigate the hindered diffusion of coal and petroleum asphaltenes in the pores of catalyst particles at elevated temperature and pressures.

2. To examine the effects of concentration, temperature, solvent type, and pressure on the intraparticle diffusivity of asphaltenes. 


\section{Executive Summary}

During this time period, the hindered diffusion of coal and petroleum asphaltenes in the pores of catalyst particles at elevated temperatures and pressures was studied. The effects of temperature on the intraparticle diffusivity of asphaltenes was examined using a coal asphaltene solute and 1-methylnaphthalene solvent diffusing into alumina catalyst pellets.

Experiments conducted to study the effects of temperature on the adsorptive diffusion of coal asphaltenes in 1-methylnaphthalene onto porous alumina showed that the molecular and effective diffusivities of the asphaltenes increased with temperature. The adsorption constant was determined by fitting the experimental diffusion uptake data with the mathematical model solution. As a result of the simulation, it was found that the logarithm of the adsorption constant was linearly dependent on temperature, and as temperature increased, the amount of adsorption decreased. The simulation results showed that the mathematical model satisfactorily fitted the adsorptive diffusion of coal asphaltenes onto alumina in a fairly wide temperature range of $55^{\circ} \mathrm{C}$ to $280^{\circ} \mathrm{C}$.

Two personnel changes occurred during this time period. One graduate student, Mr. Xiaofeng Yang, graduated with the Ph.D degree in Chemical Engineering and has taken a position in industry. Also, a new graduate student, Mr. Surya KR Vadlamani, has begun working on the project and is pursuing the M.S degree, also in Chemical Engineering. 


\section{Introduction}

Because many catalytic reactions are carried out at relatively high temperatures and pressures, it is useful to understand diffusion and adsorption behavior at elevated temperatures and pressures in order to provide reasonable judgment in catalyst design and process development. However, due to experimental difficulties, very few investigators have studied asphaltene pore diffusion and surface adsorption at high temperatures and pressures. Along this line, Seo and Massoth (1985) investigated effects of temperature on hindered diffusion of polyaromatic model compounds into alumina, and concluded that the hindrance factor $\mathrm{K}_{\mathrm{r}} \mathrm{K}_{\mathrm{p}}$ was a function of temperature. However, their temperature covered a rather limited range from $25^{\circ} \mathrm{C}$ to $50^{\circ} \mathrm{C}$.

In the current time period, we investigated effects of temperature on the adsorptive diffusion of coal asphaltenes in 1-methylnaphthalene solvent onto a porous alumina catalyst. The uptake experiments were carried out in an autoclave reactor, with temperature being controlled in a range from $55^{\circ} \mathrm{C}$ to $280^{\circ} \mathrm{C}$.

\section{$\underline{\text { Experimental Section }}$}

\section{Materials}

In adsorptive diffusion experiments, a coal asphaltene sample (C-258D) and 1methylnaphthalene (95\%, Aldrich) were used as solute and solvent, respectively. Detailed information about the coal asphaltene has been described in the previous reports ${ }^{(1-2)}$. A 
commercial alumina catalyst (Johnson Mathey, Lot \#A27E03), with a cylindrical shape, $0.33 \mathrm{~cm}$ in diameter and $0.36 \mathrm{~cm}$ in length, and having a surface area of $100 \mathrm{~m}^{2} / \mathrm{g}$, was used as the adsorption-diffusion medium. Table 1 gives some of the properties of the alumina. The original alumina sample was washed with water to remove fine particles and dusts, and dried in an oven at $120{ }^{\circ} \mathrm{C}$ overnight. The alumina was dried again in a muffle furnace at $200{ }^{\circ} \mathrm{C}$ for 4 hours and at $400{ }^{\circ} \mathrm{C}$ for 12 hours. The dried alumina was kept in a sealed bottle under $\mathrm{N}_{2}$ for later use.

\section{Apparatus and Procedures}

The diffusion-controlled adsorptive uptake of coal asphaltenes in 1methylnaphthalene onto the alumina was carried out in a magnetically stirred autoclave reactor (Parr Instrument) containing a screen wire basket for holding alumina particles.

Detailed autoclave operation procedures were described in the previous report ${ }^{(3)}$. The adsorptive uptakes were conducted at temperatures ranging from $55^{\circ} \mathrm{C}$ to $280^{\circ} \mathrm{C}$. UV spectrophotometry at $400 \mathrm{~nm}$ was used for asphaltene concentration analysis on samples taken at various time intervals during the experiments. 


\section{$\underline{\text { Results and Discussion }}$}

\section{Diffusivities and Adsorption Constants of Asphaltenes at Different Temperatures}

The molecular diffusivity of the coal asphaltene, being treated as a monodispersed compound in the solvent, can be calculated by the Stokes-Einstein equation, viz,

$$
D_{\infty}=\frac{k T}{6 \pi \eta r_{m}}
$$

and the effective diffusivity can be obtained from the following equation,

$$
D_{e}=\frac{K_{p} K_{r} \varepsilon}{\tau} D_{\infty}
$$

In above equations, the equivalent radius of the coal asphaltene $r_{m}$ was estimated as $6.4 \AA$, as shown in our previous report. The viscosities of 1-methylnaphthalene at various temperatures were obtained from the literature ${ }^{(4)}$. Using this information, the molecular and the effective diffusivities of asphaltenes at different temperatures were estimated from equations (1) and (2), respectively, with the results being shown in Table 2. From these results, it can be seen that the molecular and the effective diffusivities of asphaltenes increase greatly with temperature.

\section{Model Simulation of Asphaltene Uptake into the $\mathrm{Al}_{2} \mathrm{O}_{3}$ catalyst}

During the current time period, we used the mathematical model developed in the previous report to model experimental uptake data for the diffusion-adsorption of asphaltenes into porous alumina particles. Table 3 lists the experimental uptake data, and 
Figures 1, 2, and 3 show the experimental uptake data along with mathematical model simulations at 55,158 , and $280^{\circ} \mathrm{C}$, respectively. The detailed computer simulation procedures have been described in the previous report ${ }^{(2)}$. It should be pointed out here that for experiments at 55 and $158^{\circ} \mathrm{C}, 50$ grams of alumina sample were used; while at $280^{\circ} \mathrm{C}$, the sample weight was increased to 120 grams in order to obtain a measurable concentration decrease. This effect, increased catalyst loading, is accounted for in the mathematical model.

From Figures 1-3 it can be seen that the mathematical model fits most of the experimental data quite well. The adsorption constant $\mathrm{K}$, at each temperature was obtained by simulating the experimental data with the mathematical model, with the results being shown in Figure 4. Best fit for the dependence of the adsorption constant on temperature can be expressed as,

$$
\ln (K)=12.32-0.0218 T
$$

As shown in Figure 4 and equation (3), as temperature increases, the adsorption constant $\mathrm{K}$ decreases. This effect acting alone would result in a decrease in the adsorptive uptake rate. On the other hand, the increase in the effective diffusivity $D_{e}$ at higher temperatures, as depicted in Table 2, would tend to increase the uptake rate. These offsetting temperature dependencies resulting from $\mathrm{K}$ and $\mathrm{D}_{\mathrm{e}}$ compensate at least to some extent in the uptake process. 


\section{Conclusions}

In this time period, the adsorption-diffusion of a coal asphaltene in 1methylnaphthalene onto a porous alumina catalyst has been studied in the autoclave reactor at elevated temperatures up to $280^{\circ} \mathrm{C}$. The uptake rate of the coal asphaltenes was found to be dependent on temperature, equilibrium adsorption capacity, and diffusion rate. The logarithm of the adsorption constant was linearly dependent on temperature, and as temperature increased, the value of adsorption constant decreased. On the other hand, the effective diffusivity increased with temperature. These off-setting temperature dependencies resulting from the adsorption constant $\mathrm{K}$, and the effective diffusivity, $\mathrm{D}_{\mathrm{e}}$, compensated at least to some extent in the uptake process. Simulation results showed that the mathematical model satisfactorily fitted the adsorptive diffusion of coal asphaltenes onto alumina in a fairly wide temperature range of $55^{\circ} \mathrm{C}$ to $280^{\circ} \mathrm{C}$. 
Table 1. Properties of alumina catalyst

\begin{tabular}{|l|c|}
\hline shape & cylindrical \\
\multicolumn{1}{|c|}{ diameter, cm } & 0.33 \\
length, cm & 0.36 \\
equivalent radius, cm & 0.17 \\
surface area, $\mathrm{m}^{2} / \mathrm{g}$ & 100 \\
particle density $\rho_{\mathrm{p}}, \mathrm{g} / \mathrm{cm}^{3}$ & 1.47 \\
pore volume $\mathrm{V}_{\mathrm{p}}, \mathrm{cm}^{3} / \mathrm{g}$ & 0.39 \\
porosity $\epsilon, \mathrm{cm}^{3} / \mathrm{cm}^{3}$ & 0.57 \\
average pore diameter, $\mathrm{nm}$ & 15.6 \\
\hline
\end{tabular}

Table 2. Diffusivities of coal asphaltenes and viscosities of 1-methylnaphthalene at several temperatures.

\begin{tabular}{|c|c|c|c|}
\hline $\begin{array}{c}\mathrm{T} \\
{ }^{\circ} \mathrm{C}\end{array}$ & $\begin{array}{c}\eta^{(\mathrm{a})} \\
\mathrm{cP}\end{array}$ & $\begin{array}{c}\mathrm{D}_{\infty} \mathrm{x} 10^{6} \\
\mathrm{~cm}^{2} / \mathrm{s}\end{array}$ & $\begin{array}{c}\mathrm{D}_{\mathrm{e}}{ }^{(\mathrm{b})} \times 10^{6} \\
\mathrm{~cm}^{2} / \mathrm{s}\end{array}$ \\
\hline 55 & 1.45 & 0.43 & 0.057 \\
\hline 158 & 0.45 & 4.0 & 0.53 \\
\hline 280 & 0.24 & 13.5 & 1.79 \\
\hline
\end{tabular}

(a). Estimated according to Yaws' handbook ${ }^{(4)}$.

(b). Calculated by assuming a tortuosity factor of 3 . 
Table 3. Experimental uptake data for coal asphaltene/1- methylnaphthalene/ alumina system at several temperatures.

\begin{tabular}{||c|c|c|c|c|c||}
\hline \multicolumn{2}{||c|}{$\begin{array}{c}\text { Temperature: } 55{ }^{\circ} \mathrm{C} \\
\mathrm{Al}_{2} \mathrm{O}_{3} \text { weight: } 50 \mathrm{~g}\end{array}$} & \multicolumn{2}{|c|}{$\begin{array}{c}\text { Temperature: } 158{ }^{\circ} \mathrm{C} \\
\mathrm{Al}_{2} \mathrm{O}_{3} \text { weight: } 50 \mathrm{~g}\end{array}$} & \multicolumn{2}{c||}{$\begin{array}{c}\text { Temperature: } 280{ }^{\circ} \mathrm{C} \\
\mathrm{Al}_{2} \mathrm{O}_{3} \text { weight: } 120 \mathrm{~g}\end{array}$} \\
\hline $\mathrm{t}, \mathrm{hr}$. & $\mathrm{C} / \mathrm{C}_{0}$ & $\mathrm{t}, \mathrm{hr}$. & $\mathrm{C} / \mathrm{C}_{0}$ & $\mathrm{t}, \mathrm{hr}$. & $\mathrm{C}_{0}$ \\
\hline 0.00 & 1.00 & 0.00 & 1.00 & 0.00 & 0.40 \\
\hline 0.53 & 0.80 & 0.4 & 0.78 & 1.00 & 0.80 \\
\hline 1.51 & 0.66 & 1.3 & 0.71 & 2.50 & 0.75 \\
\hline 4.20 & 0.56 & 4.3 & 0.67 & 8.60 & 0.72 \\
\hline 10.3 & 0.49 & 10.6 & 0.65 & & \\
\hline 20.4 & 0.45 & 22 & 0.66 & & \\
\hline
\end{tabular}




\section{$\underline{\text { Nomenclature }}$}

$\begin{array}{ll}\mathrm{D} \infty & \text { molecular diffusivity, } \mathrm{cm}^{2} / \mathrm{s} \\ \mathrm{D}_{\mathrm{e}} & \text { effective diffusivity, } \mathrm{cm}^{2} / \mathrm{s} \\ \mathrm{k} & \text { Boltzmann's constant, } 1.385 \times 10^{-6} \mathrm{erg} /{ }^{0} \mathrm{~K} \\ \mathrm{~K} & \text { linear adsorption constant, } \mathrm{cm}^{3} \text { - solution } / \mathrm{g} \text {-catalyst } \\ \mathrm{K}_{\mathrm{p}} & \text { partition factor } \\ \mathrm{K}_{\mathrm{r}} & \text { restriction factor } \\ \mathrm{r}_{\mathrm{m}} & \text { molecule radius, } \mathrm{A}^{0} \\ \mathrm{t} & \text { time, } \mathrm{h} \\ \mathrm{T} & \text { temperature, } \mathrm{K}\end{array}$

Greek letters

$\eta \quad$ solvent viscosity, $\mathrm{g} / \mathrm{cm}-\mathrm{s}$

$\varepsilon \quad$ catalyst porosity

$\tau \quad$ catalyst tortuosity factor 


\section{$\underline{\text { References }}$}

1. DOE Report No. 95221r02, 1996: "Hindered Diffusion of Asphaltenes at Elevated Temperature and Pressure".

2. DOE Report No. 95221r04, 1997: "Hindered Diffusion of Asphaltenes at Elevated Temperature and Pressure".

3. DOE Report No. 95221r03, 1997: "Hindered Diffusion of Asphaltenes at Elevated Temperature and Pressure".

4. Carl L. Yaws, "Handbook of Viscosity", Gulf Publishing Company, Vol 3, p227, 1995. 
Figure 1. Model simulation for the uptake of coal asphaltenes in 1-methylnaphthalene onto alumina at $55^{\circ} \mathrm{C}$

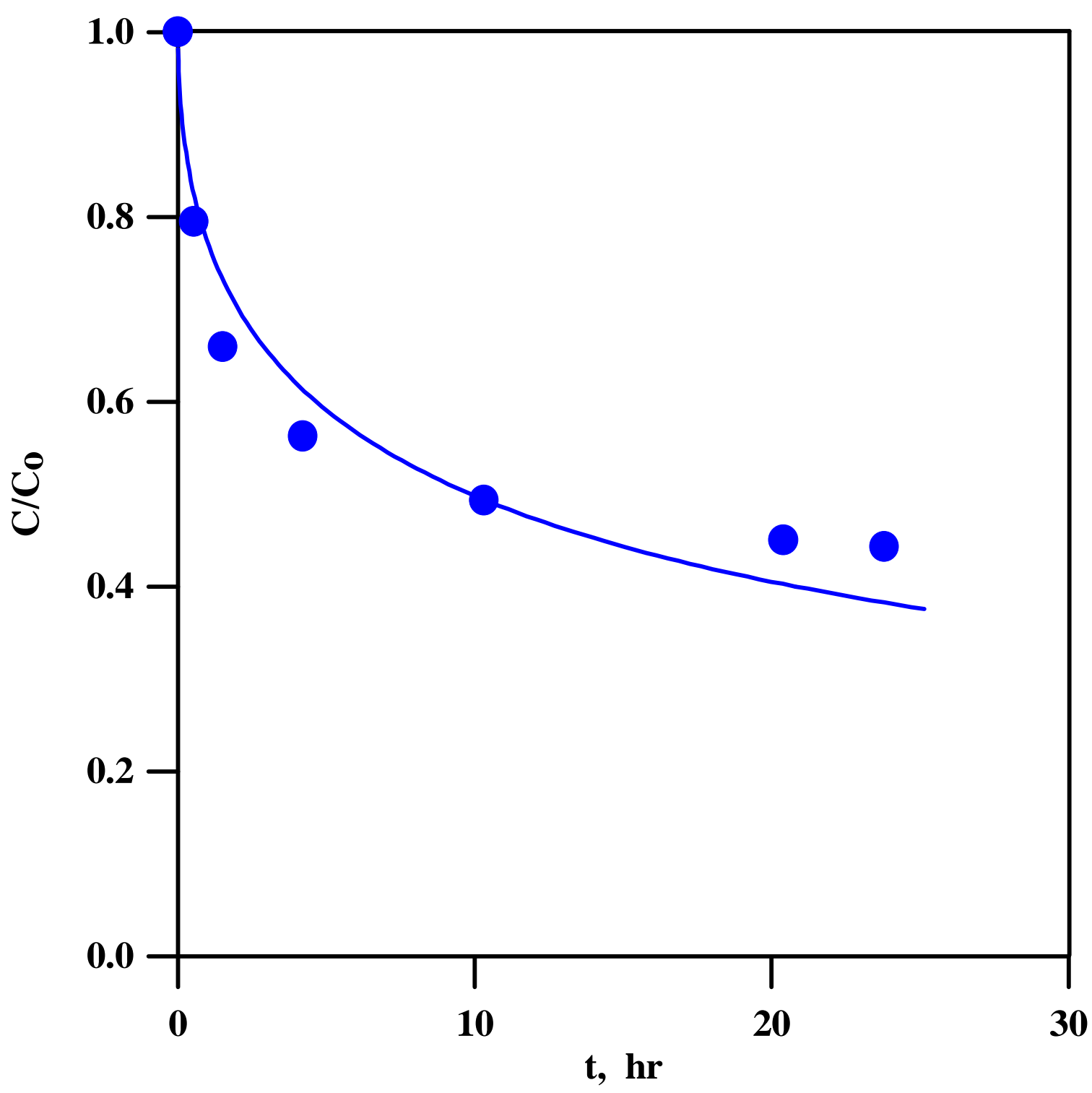


Figure 2. Model simulation for the uptake of coal asphaltenes in 1-methylnaphthalene onto alumina at $158^{\circ} \mathrm{C}$

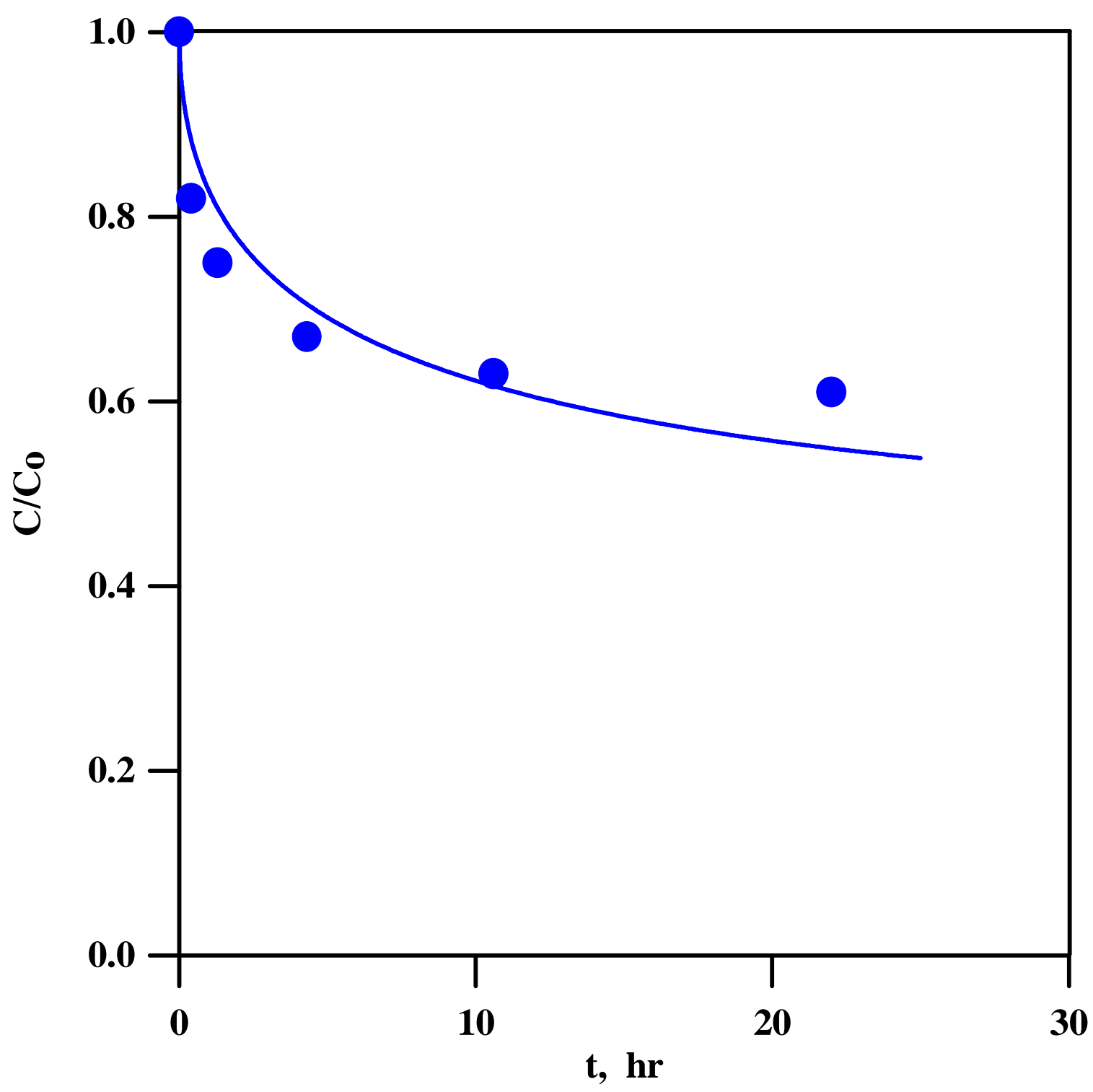


Figure 3. Model simulation for the uptake of coal asphaltenes in 1-methylnaphthalene onto alumina at $280^{\circ} \mathrm{C}$

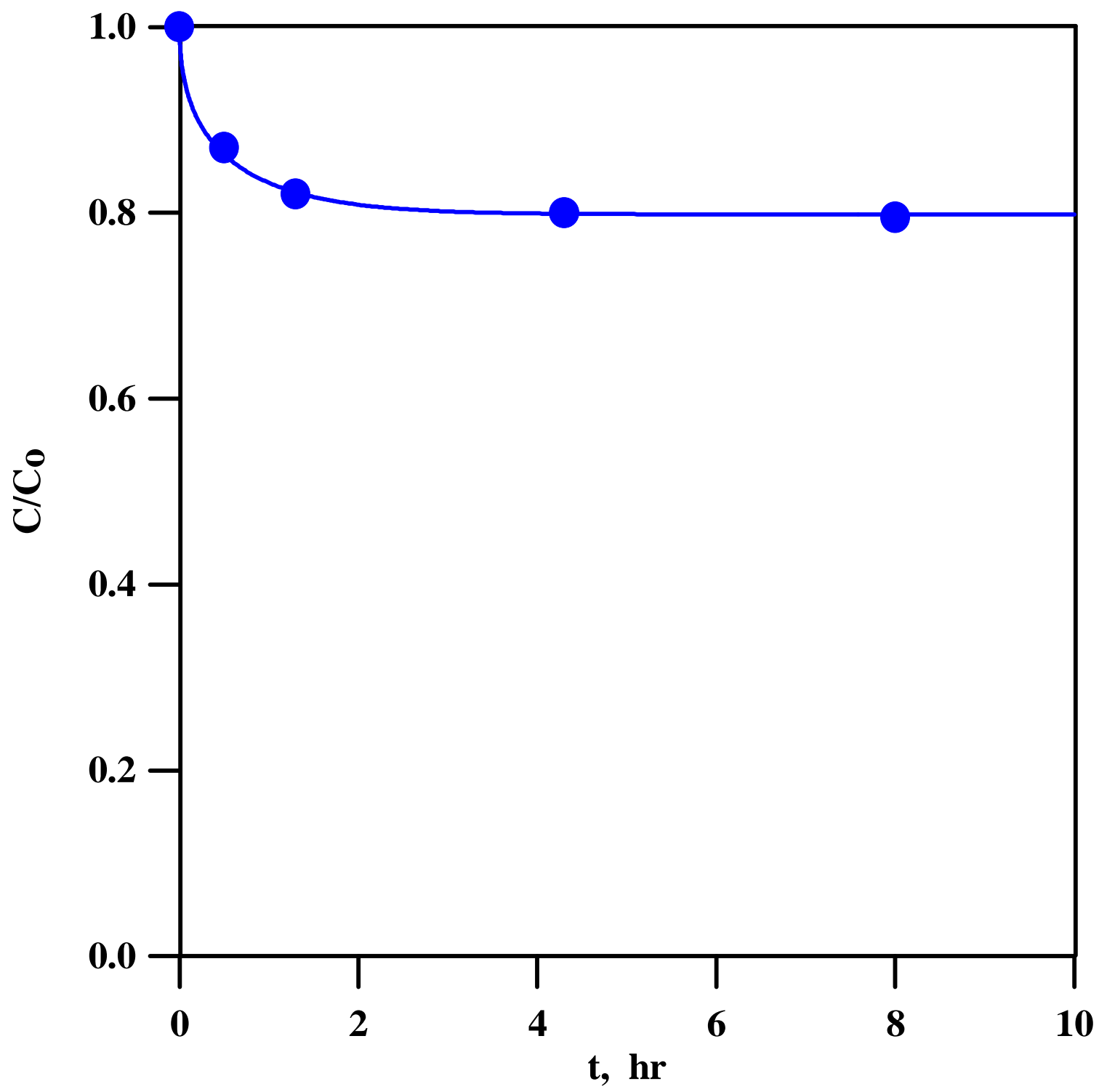


Figure 4. Adsorption constant vs temperature for the uptake of coal asphaltenes in 1methylnaphthalene onto alumina

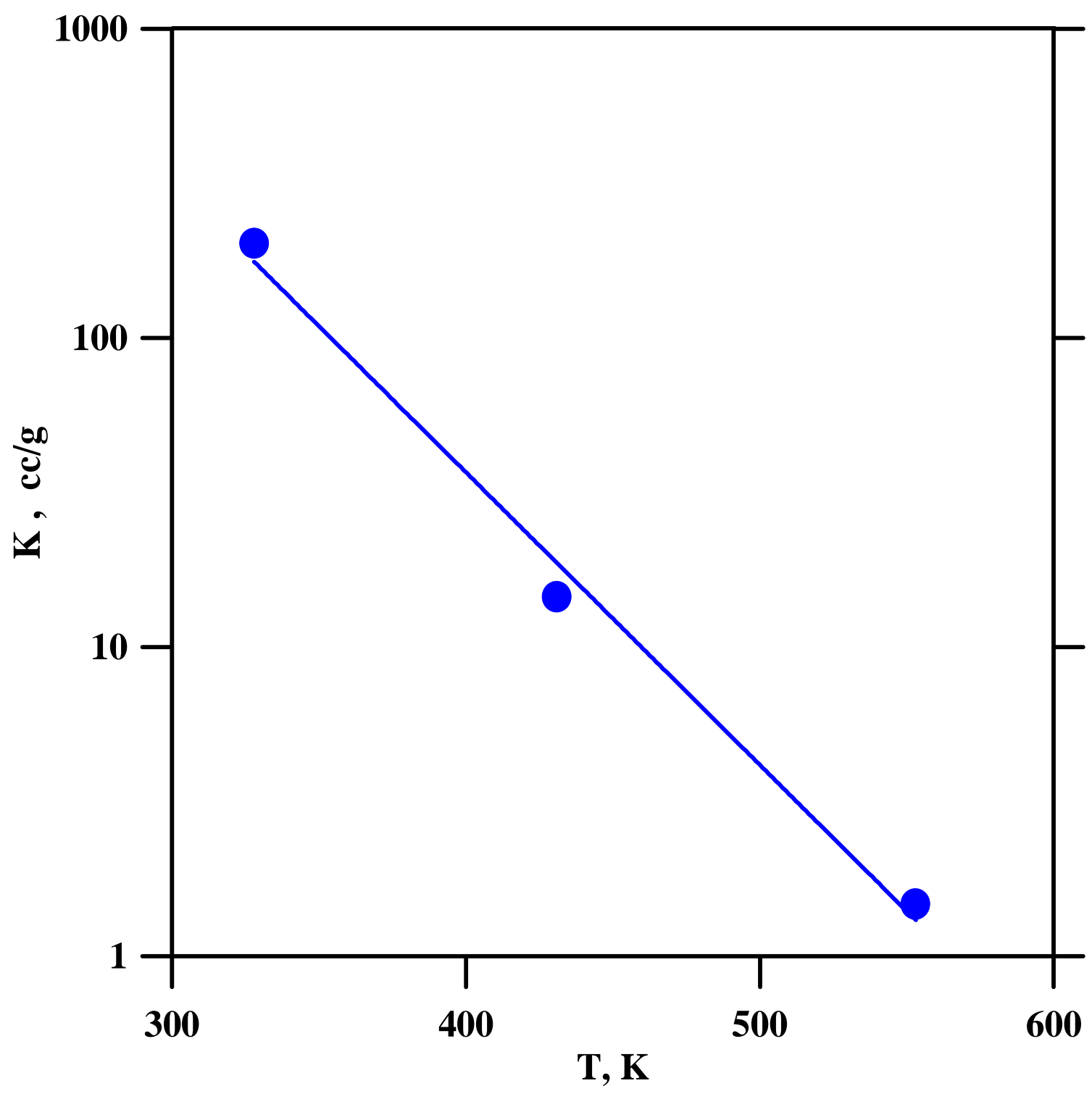




\section{Planned Work}

During the next time period we plan to further investigate diffusion and adsorption of asphaltenes and model compounds at higher temperatures and pressures in a microautoclave reactor. Comparisons between the adsorptive diffusion of coal and petroleum asphaltenes will be made. Different solvents will be used to investigate the effects of solvent on the behavior of asphaltene diffusion and adsorption in porous catalysts. This work is planned to be carried out by a new M.S. student, Mr. Surya Vadlamani, who began his M.S. research in January, 1998. 